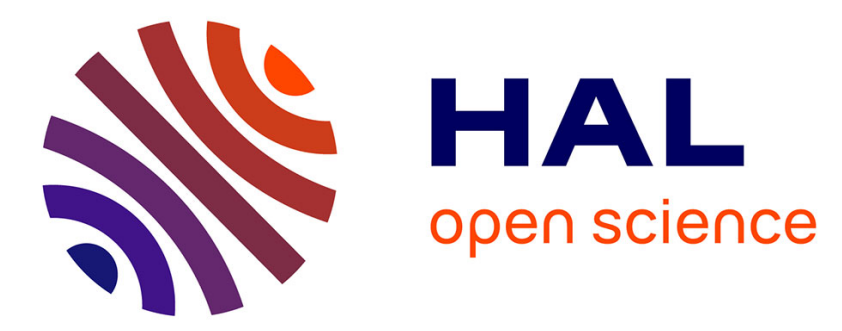

\title{
Adaptive time-stepping analysis of nonlinear microwave heating problems
}

\author{
A. A. Rabello, E. J. Silva, R. R. Saldanha, Christian Vollaire, Alain Nicolas
}

\section{To cite this version:}

A. A. Rabello, E. J. Silva, R. R. Saldanha, Christian Vollaire, Alain Nicolas. Adaptive time-stepping analysis of nonlinear microwave heating problems. IEEE Transactions on Magnetics, 2005, 41 (5), pp.1584-1587. 10.1109/TMAG.2005.845034 . hal-00141459

\section{HAL Id: hal-00141459 \\ https://hal.science/hal-00141459}

Submitted on 18 Apr 2007

HAL is a multi-disciplinary open access archive for the deposit and dissemination of scientific research documents, whether they are published or not. The documents may come from teaching and research institutions in France or abroad, or from public or private research centers.
L'archive ouverte pluridisciplinaire HAL, est destinée au dépôt et à la diffusion de documents scientifiques de niveau recherche, publiés ou non, émanant des établissements d'enseignement et de recherche français ou étrangers, des laboratoires publics ou privés. 


\title{
Adaptive Time-Stepping Analysis of Nonlinear Microwave Heating Problems
}

\author{
Anderson Arhtur Rabello ${ }^{1}$, Elson José Silva ${ }^{1}$, Rodney Rezende Saldanha ${ }^{1}$, Christian Vollaire ${ }^{2}$, and Alain Nicolas ${ }^{2}$ \\ ${ }^{1}$ Departamento de Engenharia Elétrica, Universidade Federal de Minas Gerais, Belo Horizonte 31270-901, Brazil \\ ${ }^{2}$ CEGELY, Ecole Centrale de Lyon, 69134 Ecully Cedex, France
}

\begin{abstract}
This paper presents a three-dimensional computational model for nonlinear microwave heating problems. In order to reduce the computational costs, a new finite element method adaptive time-stepping scheme is proposed. Numerical results are compared with experimental measurements on a problem of dielectric heating of water.
\end{abstract}

Index Terms-Adaptive time-stepping, finite element method (FEM), microwave heating, nonlinear dielectric properties.

\section{INTRODUCTION}

$\mathbf{N}$ UMERICAL schemes have been employed to solve the coupled wave and thermal diffusion equations [1], [2]. In order to increase the accuracy of the results, a coupled FEM scheme was implemented and validated in [3]. Processing of materials at microwave frequencies is made difficult by physical properties witch are strongly dependent on the temperature. As a consequence, small changes in the temperature of the samples may cause large changes in the electric field distribution. Thus, the importance in reducing the computational costs in these schemes is related with the nonlinear response of the material properties with temperature.

The frequency domain solution of the electrical field may be employed in weak coupled problems if the time of thermal heating sample exposition is considered substantially larger than the time necessary for the electromagnetic phenomena stabilization [4]. The large difference between the two scales of time allows the power distribution to be calculated according to the initial dielectric property information. Thus, adapting the timestepping by knowing the temperature evolution in time may reduce the total time of simulation. An adaptive time-stepping procedure was employed by [5] to minimize the total time for reaching the steady-state solution in "batch" thermal problems. In order to reduce the total time of simulation in the continuous heating processes, the time step may be adapted to the limits of electrical field variation. This work presents a finite element model (FEM) adaptive time-stepping scheme for solving a coupled thermoelectromagnetic heating problem within a three-dimensional (3-D) FEM. The dependence of its dielectric properties on temperature is considered and it is shown that number of iterations is reduced without significant loss of accuracy.

\section{Formulation OF THE PROBLEM}

\section{A. Electromagnetic Problem}

To develop the numerical model, we consider a typical configuration as shown in Fig. 1. It is comprised by a rectangular waveguide with a lossy dielectric load [1]. The guide is of width

Digital Object Identifier 10.1109/TMAG.2005.845034

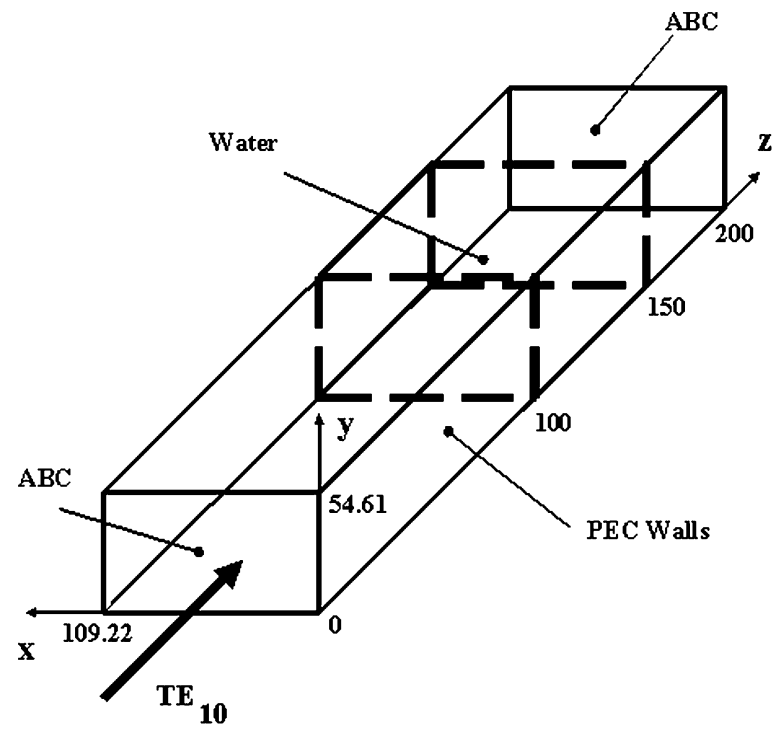

Fig. 1. Analytical model (dimensions in millimeters).

$(a)$ in $(x)$ direction and height $(b)$ in $(y)$ direction and extends in the axial $(z)$ direction. The domain of study is limited inside the waveguide.

The incident mode is the transverse electric $\mathrm{TE}_{10}$

$$
\begin{aligned}
\mathbf{E}_{\mathrm{inc}}= & E_{0} \sin \left(\frac{\pi x}{a}\right) e^{-j \beta z} \hat{y} \\
\mathbf{H}_{\mathrm{inc}}= & {\left[\frac{\beta}{\mu_{0} \omega} \sin \left(\frac{\pi x}{a}\right) \hat{x}+j \frac{\pi}{\alpha \mu_{0} \omega} \cos \left(\frac{\pi x}{a}\right) \hat{z}\right] } \\
& \times e^{-j \beta z} \hat{y}
\end{aligned}
$$

where $E_{0}$ is the strength of the field, $\beta=\sqrt{(\omega / c)^{2}-(\pi / a)^{2}}$ is the wave number of the propagating mode, $\omega$ is the source frequency, $c$ and $\mu_{0}$ are, respectively, the speed of light and the magnetic permeability in the vacuum. The incident average power is given by

$$
P_{\text {inc }}=\frac{E_{0}^{2} a b}{4 Z_{\mathrm{TE}}}
$$

where $Z_{\mathrm{TE}}$ is the wave impedance defined as

$$
Z_{\mathrm{TE}}=-\frac{E_{y}}{H_{x}}=\frac{\mu_{0} \omega}{\beta}=\mu_{0} \omega\left[\left(\frac{\omega}{c}\right)^{2}-\left(\frac{\pi}{a}\right)^{2}\right]^{-(1 / 2)} .
$$


The time harmonic electromagnetic fields in the guide are described by Maxwell's equations

$$
\begin{aligned}
\nabla \times \mathbf{E} & =-j \omega \mu_{0} \mathbf{H} \\
\nabla \times \mathbf{H} & =j \omega \varepsilon_{0} \varepsilon_{r}^{*} \mathbf{E} .
\end{aligned}
$$

The material properties are the conductivity $\sigma$ and the complex permittivity $\varepsilon^{*}$ defined by

$$
\varepsilon_{r}^{*} \equiv \varepsilon-j \frac{\sigma}{\omega} \equiv \varepsilon^{\prime}-j \varepsilon^{\prime \prime} .
$$

In microwave heating problems, the magnetic permeability is well approximated by its free space value. Additionally, the models consider slow change of the properties relative to the frequency. In principle, the conductivity response function and dielectric response function contribute to both $\varepsilon^{\prime}$ and $\varepsilon^{\prime \prime}$. If one measures $\varepsilon^{\prime}$ and $\varepsilon^{\prime \prime}$ separately it is not possible to identify the particular contribution of $\sigma$ and $\varepsilon$ without a theoretical model. However, considering the experimental results of [6], the relative permittivity and loss factor of several dielectric materials may be described as a parabolic function of temperature $(T)$ at microwave frequencies

$$
\begin{aligned}
\varepsilon^{\prime} & =C_{0} T^{2}+C_{1} T+C_{2} \\
\varepsilon^{\prime \prime} & =C_{3} T^{2}+C_{4} T+C_{5}
\end{aligned}
$$

where $C_{0}, C_{1}, C_{2}, C_{3}, C_{4}, C_{5}$, are constants and $\mathbf{E}$ is the electrical field.

\section{B. Thermal Problem}

The heat diffusion equation is described by

$$
\rho c_{p} \frac{\partial T}{\partial t}=\nabla \cdot(\kappa \nabla T)+Q
$$

where $\kappa$ is the thermal conductivity, $\rho$ is the sample density, $c_{P}$ is the specific heat capacity, and $t$ is the time. Using the Poynting vector for harmonic fields the source $Q$ in (10) is equal to the power dissipated per unit volume

$$
P_{\text {diss }}=\frac{1}{2} \omega \varepsilon_{0}\left(C_{3} T^{2}+C_{4} T+C_{5}\right) \cdot|E|^{2} .
$$

The initial and boundary conditions are

$$
\begin{aligned}
T & =g(x, y, z) \text { at } t=0 \\
T & =f(x, y, z) \text { on } \Gamma_{T} \\
\kappa \frac{\partial T}{\partial n}+q+h\left(T-T_{a}\right) & =0 \text { on } \Gamma_{q}
\end{aligned}
$$

where $\left(\Gamma_{T}\right)$ and $\left(\Gamma_{q}\right)$ represent the portions of the boundary of the water layer at which its conditions are of essential and natural type, respectively, $(q)$ is the specified heat flux at the boundary, $(h)$ is the convective heat transfer coefficient, $\left(T_{a}\right)$ is the ambient temperature, and $(n)$ is the direction of the unit outward normal vector to $\left(\Gamma_{q}\right)$.

In this work, the radiation effect can be considered negligible, because of the low temperature profiles.

\section{FEM FORMULATION}

In order to solve (10), the volume V, bounded by the waveguide walls, was meshed with tetrahedral elements. The temperature being a scalar, there is no discontinuity with the interface between various media. Consequently, this domain is discretized by the nodal finite element method using the following product solution approximation:

$$
T_{e}(x, y, z ; t)=\sum_{i=1}^{4} N_{i}(x, y, z) T_{i}(t)
$$

where $N_{i}$ and $T_{i}$ are, respectively, the basis function at the node $i$ at instant $t$ and $T_{e}$ the temperature inside a finite element.

Then, the semidiscretized form of (10) may be expressed by the following equations in the domain with volume $V_{e}$ and surface $S_{e}$ of each element:

$$
R_{e} \frac{\partial T_{i}}{\partial t}+S_{e} T_{i}-f_{e}=0
$$

where

$$
\begin{aligned}
R_{e} & =\rho c_{p} \int_{V_{e}} N_{i} N_{j} d V_{e} \\
S_{e} & =\int_{V_{e}} \kappa\left(\nabla N_{i} \nabla N_{j}\right) d V_{e}+\int_{S_{e}} h N_{i} N_{j} d S_{e} \\
f_{e} & =\int_{V_{e}} Q N_{j} d V_{e}+\int_{S_{e}} h T_{a} N_{j} d S_{e} .
\end{aligned}
$$

Considering the backward time integration scheme, the fully discretized residual of (10) may be expressed by

$$
r(T)=\left(R+\Delta t_{n} S\right) T^{n+1}-R T^{n}-\Delta t_{n} f_{n} .
$$

The following algorithm is employed to consider the nonlinear dependence on temperature of (11):

$$
\begin{aligned}
\left(R+\Delta t_{k} S\right) \delta T^{k} & =r\left(T^{k}\right) \\
T^{k+1} & =T^{k}+\delta T^{k} \\
k & \leftarrow k+1 .
\end{aligned}
$$

The steps (21)-(23) are repeated until the residual $\delta T^{k}$ is approximated to zero. So, $T^{k+1}$ is attributed to the corrected temperature $T^{n+1}$.

Finite element time domain solutions have the following time step size stability requirement

$$
\Delta t \leq \frac{2 \rho c_{P}\left(\Delta x^{2}\right)}{3 \kappa}
$$

where $\Delta x$ is the linear dimension of the element based on mesh geometry [4].

In order to determine the electrical field and the source term in (11), the Maxwell's equations may be applied to the waveguide. Flexibility of the FE technique and right physical sense of the edge elements make this method useful to discretize the wave (25). The use of the finite element method for both thermal and electromagnetic model allows using the same mesh. So, the 


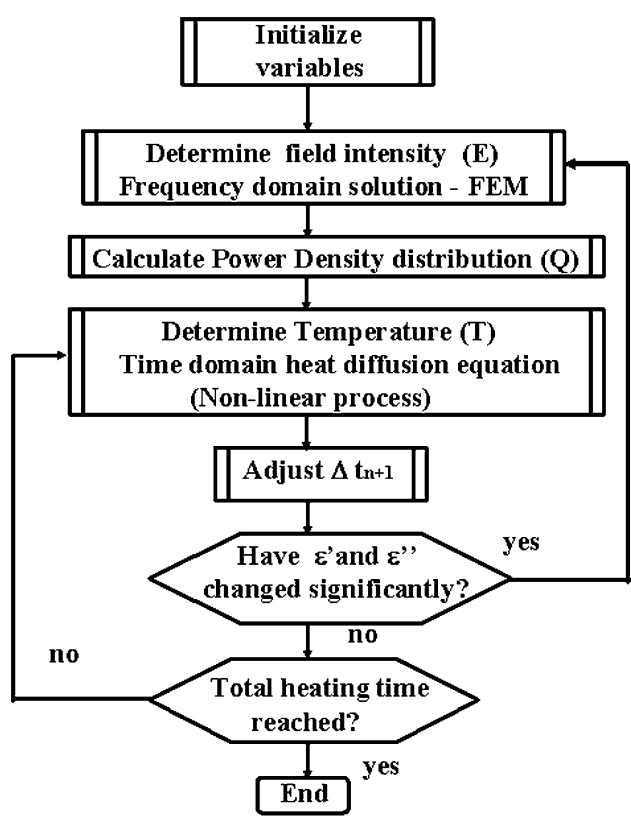

Fig. 2. Flowchart of microwave heating analysis.

source term coming from the electromagnetic model is computed on the nodes of the mesh and directly taking into account in the thermal model

$$
\begin{aligned}
& -\int_{V}(\nabla \times \mathbf{W}) \cdot(\nabla \times \mathbf{E}) d V-\int_{V} k_{0}^{2} \varepsilon \mathbf{W} \cdot \mathbf{E} d V \\
& +\int_{S_{\mathrm{ABC}}} j k_{0} \mathbf{W} \cdot \mathbf{E}_{t} d S \\
& =\int_{S_{\mathrm{ABC}}} \mathbf{W} \cdot\left(j k_{0} \cdot \mathbf{E}_{t}^{i} d S-\mathbf{n} \times \nabla \times \mathbf{E}^{i}\right) d S
\end{aligned}
$$

where $S_{\mathrm{ABC}}$ defines the incident and outgoing surface of the waveguide (see Fig. 1) where the ABC are introduced and $\mathbf{W}$ is the vector basis function associated with the edges of the elements [7]. First-order Engquist Majda absorbing boundary conditions $(\mathrm{ABC})$ are introduced at the ends of the waveguide.

\section{ADAPTIVE TIME STEPPING}

This work attempts to model the heating profile using time steps to estimate the material properties and thermal motion as seen in the flowchart of Fig. 2.

The maximum change in the dielectric property will be the most significant factor to control the nonlinear process. In [2], this information was only employed to reduce the number of calls of the electric field solution. However, analogous criterion may be also employed to reduce the number of iterations of the temperature solution loop in weak coupled microwave heating problems.

The corrected and the predicted temperature in time step $n$ may be used to evaluate the changes in the dielectric properties into the loop of the temperature. Thus, the optimal next time step $\Delta t_{n+1}$ at the end of iteration $n$ will be the maximum value that does not yield significant changes in electric field profiles or instabilities in solutions. The temperature values are estimated in the barycenter of each element $i$, and they are used to obtain the dielectric properties considered homogeneous into the element. The new adaptive time-stepping algorithm is summarized as follows.

1) Estimate the maximum predicted time-stepping $\Delta t_{n+1}$ adopted in each time step. The criterion (24) is used in this work.

2) Obtain the rate of change of the temperature $T_{i}^{\prime n-1}$ of the previous time step using the following finite-difference relation:

$$
\begin{aligned}
& T_{i}^{\prime n-1}=\frac{\Delta t_{n-2}}{\Delta t_{n-1}+\Delta t_{n-2}}\left(\frac{T_{i}^{n}-T_{i}^{n-1}}{\Delta t_{n-1}}\right) \\
& +\frac{\Delta t_{n-1}}{\Delta t_{n-1}+\Delta t_{n-2}}\left(\frac{T_{i}^{n-1}-T_{i}^{n-2}}{\Delta t_{n-2}}\right) .
\end{aligned}
$$

3) Obtain the derivate estimation of temperature $T_{i}^{\prime n}$ for the current time step using the trapezoid rule

$$
T_{i}^{\prime n}=\frac{2}{\Delta t_{n-1}}\left(T_{i}^{n}-T_{i}^{n-1}\right)-T_{i}^{\prime n-1} .
$$

4) Obtain the predicted $T_{i, p}^{n+1}$ the predicted temperature values in each element $i$ using the Adams-Bashfort predictor

$T_{i, P}^{n+1}=T_{i}^{n}+\frac{\Delta t_{n}}{2}\left[\left(2+\frac{\Delta t_{n}}{\Delta t_{n-1}}\right)\right] T_{i}^{\prime n}-\frac{\Delta t_{n}}{\Delta t_{n-1}} T_{i}^{\prime n-1}$.

5) Calculate the corrected and the predicted $\varepsilon_{i, P}^{*}$ values of the dielectric properties of the material for the next time step

$$
\begin{aligned}
\varepsilon_{i}^{*}= & C_{0}\left(T_{i}^{n+1}\right)^{2}+C_{1}\left(T_{i}^{n+1}\right)+C_{2} \\
& -j\left[C_{3}\left(T_{i}^{n+1}\right)^{2}+C_{4}\left(T_{i}^{n+1}\right)+C_{5}\right] \\
\varepsilon_{i, P}^{*}= & C_{0}\left(T_{i, P}^{n+1}\right)^{2}+C_{1}\left(T_{i, P}^{n+1}\right)+C_{2} \\
& -j\left[C_{3}\left(T_{i, P}^{n+1}\right)^{2}+C_{4}\left(T_{i, P}^{n+1}\right)+C_{5}\right] .
\end{aligned}
$$

6) The maximum predicted time-stepping is decremented and the steps 2 to 5 are repeated until the limit where the following criteria based on the electrical properties variation is fulfilled

$$
\sum_{i=1}^{n}\left|\operatorname{Re}\left\{\varepsilon_{i}^{*}-\varepsilon_{i, P}^{*}\right\}\right| \leq \sum_{i=1}^{n}\left|\gamma \operatorname{Re}\left\{\varepsilon_{i}^{*}\right\}\right| .
$$

In (31), $n$ is the total number of elements inside the water layer and $\gamma$ is the limit based on the maximum $\varepsilon^{\prime}$ change permitted. The same criterion is adopted for the imaginary part.

\section{RESULTS}

The heating of a water layer was investigated numerically. The electromagnetic and thermal properties used in the computations are shown in Tables I and II.

The incident power $P_{\text {inc }}=300 \mathrm{~W}$ is applied to the guide which yields $E_{0}$ equal $9570 \mathrm{Vm}^{-1}$ (3). Fig. 3 shows the penetration of the electric field in water. The results of temperature 
TABLE I

DIELECTRIC CONSTANTS

\begin{tabular}{ll}
\hline \multicolumn{2}{c}{ Water } \\
\hline$C_{0}$ & -0.0022 \\
$C_{2}$ & -0.1140 \\
$C_{2}$ & 80.6759 \\
$C_{3}$ & 0.0049 \\
$C_{4}$ & -0.6451 \\
$C_{5}$ & 25.9115 \\
\hline
\end{tabular}

TABLE II

THERMAL PROPERTIES

\begin{tabular}{lcc}
\hline & Air & Water \\
\hline$\kappa(\mathrm{W} / \mathrm{m} \mathrm{K})$ & 0.024 & 0.556 \\
$\rho(\mathrm{Kg} / \mathrm{m})$ & 1.205 & 1000 \\
$\mathrm{C}_{\mathrm{p}}(\mathrm{J} / \mathrm{Kg} \mathrm{K})$ & 1007 & 4186 \\
$\mathrm{~h}(\mathrm{~W} / \mathrm{m} \mathrm{K})$ & 5 & - \\
\hline
\end{tabular}

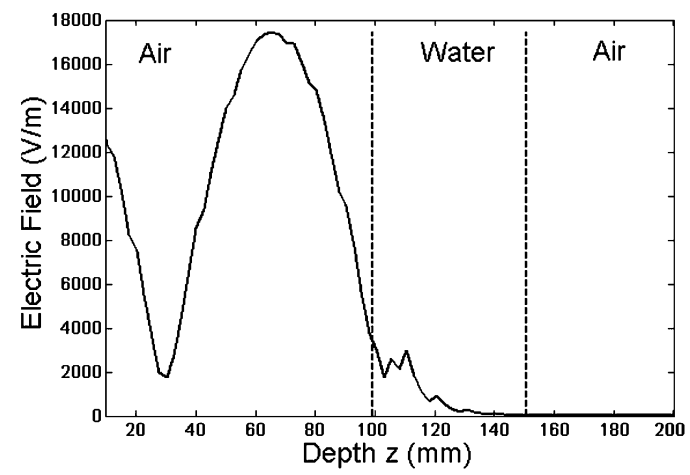

Fig. 3. Penetration depth of electric field in waveguide in YOZ plane, $x=$ $54.61 \mathrm{~mm}$.

profiles are compared with the previous results [1] as follow in Fig. 4.

A PC $2.4 \mathrm{GHz}$ was used to obtain the numerical results. The domain was meshed with 188832 elements and the total time of processing was about $1380 \mathrm{~min}(23 \mathrm{~h})$ without the time-stepping adaptive algorithm. Table III shows the results of the simulation by varying the proprieties in sample and the error $\gamma$ considered. The values of $\gamma$ are sufficiently small in order to maintain the relative error in the solution.

The number of iterations is significantly reduced in the adaptive time step loop when $\gamma$ increases. In all cases the total processing time is reduced compared to the fixed time step.

\section{CONCLUSION}

A coupled magnetothermal model was presented. Because of the differences in thermal and electromagnetic time-constants, non linearities introduced by the changes of temperature and the properties of the variables to the interfaces between mediums the thermal model is discretized by nodal FE in time domain

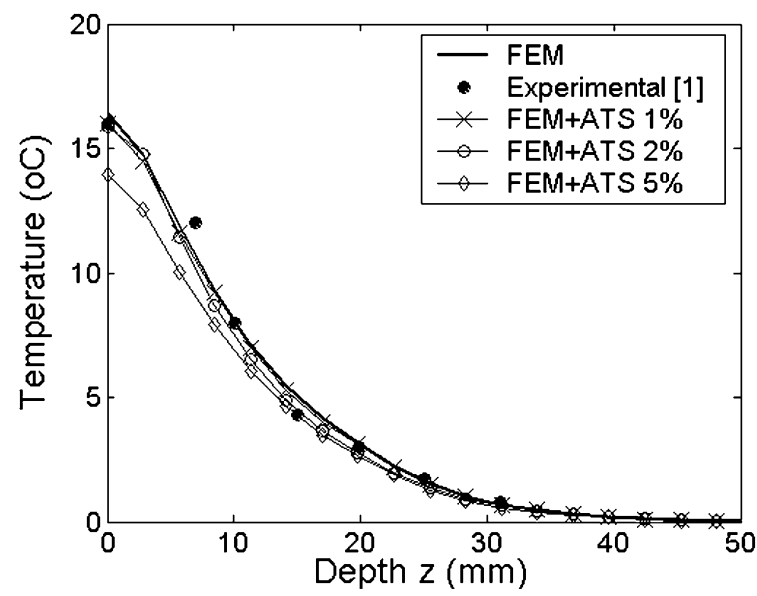

Fig. 4. Comparison between temperature profiles in water after $30 \mathrm{~s}$ in $\mathrm{YOZ}$ plane, $x=54.61 \mathrm{~mm}$. The adaptive time-stepping algorithm was included in FEM solution for $\gamma=1 \%, \gamma=2 \%$, and $\gamma=5 \%$.

TABLE III

NUMERICAL RESULTS-WATER SAMPLE

\begin{tabular}{lccc}
\hline & $\gamma=1 \%$ & $\gamma=2 \%$ & $\gamma=5 \%$ \\
\hline $\begin{array}{l}\text { Number of } \\
\begin{array}{l}\text { Calls Electric } \\
\text { Field Loop }\end{array}\end{array}$ & 11 & 3 & 2 \\
$\begin{array}{l}\text { Number Total } \\
\text { of Iterations }\end{array}$ & 27 & 13 & 6 \\
$\begin{array}{l}\text { Relative } \\
\text { Error (\%) }\end{array}$ & 2 & 4 & 15 \\
$\begin{array}{l}\text { Total Processing } \\
\text { Time (h) }\end{array}$ & 4 & 1 & 0.5 \\
\hline
\end{tabular}

and the electromagnetic model is discretized by edge FE in frequency domain. The computing time was considerably reduced by using an algorithm of adaptive time-stepping that does not generate a loss of precision of the result. So, this type of model can be used for the design of complex industrial systems.

\section{REFERENCES}

[1] I. P. Ratanadecho, K. Aoki, and M. Akahori, "A numerical and experimental investigation of the modeling of microwave heating for liquid layers using a rectangular wave guide," Appl. Math. Modeling, vol. 26, pp. 449-472, 2002.

[2] H. Zhao and I. W. Turner, "The use of a coupled computational model for studying the microwave heating of wood," Appl. Math. Modeling, vol. 24, pp. 183-197, 2000.

[3] A. A. Rabello, C. Vollaire, and E. J. Silva, "Modélization 3-D de Dispositifs de Chauffage Par Micro Ondes," presented at the NUMELEC, Toulouse, France, 2003, CD-ROM.

[4] J. Braunstein, K. Connor, S. Salon, and L. Libelo, "Investigation of microwave heating with time varying material properties," IEEE Trans. Magn., vol. 35, no. 3, pp. 1813-1816, May 1999.

[5] A. S. França and K. Haghighi, "Adaptive finite element analysis of transient thermal problems," Num. Heat Transfer, vol. 26, pp. 273-292, Apr. 1994.

[6] A. R. von Hippel, Dielectric Materials and Applications. Cambridge, MA: MIT Press, 1954.

[7] J. F. Lee and R. Mitra, "A note on the application of edge-elements for modeling three-dimensional cavities," IEEE Trans. Microw. Theory Tech., vol. 40, no. 5, pp. 1767-1773, May 1992.

Manuscript received June 8, 2004. 